\title{
PRODUCTOS DE EROSIÓN DE LAS ROCAS INTRUSIVAS Y PLAGIO- GRANITOS DEL COMPLEJO OFIOLÍTICO DE NICOYA, COSTA RICA
}

\author{
Claudio Calvo \\ Anna-Peters-Str. 51c, 70597 Stuttgart, Alemania
}

(Recibido 14/12/1998; Aceptado 8/2/1999)

\begin{abstract}
This study calls attention to the occurrence of plutonic detritus in cretaceous forearc sandstones from northwestern Costa Rica. Plutonic rock fragments are overlooked accessory particles, commonly present in pyroxene-bearing sandstones overlying the Nicoya ophiolite complex. Based on the modal analysis of framework grains, I analized three sandstone suites of the El Viejo and Rivas Formations which include both shallow and deepwater facies, ranging from Late Campanian to Maastrichtian in age. In terms of primary framework components, sandstones bearing plutonic detritus are similar to those derived from magmatic arcs. Two modal parameters are introduced to evaluate plutonic contributions. These are defined as the ratio of plutonic to total lithic fragments $(\mathrm{Lp}+$ intercrec.QF/Lt) and the ratio of uralitized pyroxene to total pyroxene grains (uralPx/Px). Modal values for $\mathrm{Lp}+$ intercrec.QF/Lt indicate that plutonic fragments average up to $9 \%$ of total lithics. The strong relationship between both parameters suggests that uralitized pyroxene grains also result from intrusive rocks. Source rocks probably correspond with basic and intermediate intrusive rocks, like gabbros, dolerites, and diorites. In particular, high concentrations of lithic fragments exhibiting micrographic textures and uralitized pyroxene grains are interpreted to be principally derived from eroded plagiogranitic intrusions. Moreover, sandstone ages based on large foraminiferal assemblages indicate a pre-Late Campanian age for these intrusions. Distribution of sandstone suites records provenance areas located on Nicoya Peninsula as well as in the area of Cerro Barbudal, north of the Golf of Nicoya. Sandstones suites containing plutonic detritus signal incipient unroofing of low levels of the Mesozoic ophiolitic sequence in the Late Campanian and Maastrichtian times. In consecuence, plutonic and associated radiolarian cherts grains can be used as detrital paleotectonic indicators of vertical uplift of the Costa Rican orogen during the Late Cretaceous. This tectonic event is consistent with the onset of the Laramide orogeny. Field observations reveal that intrusive rocks within the Nicoya Complex even today represent a miscellaneous source of sediment in northwestern Costa Rica.
\end{abstract}

RESUMEN: En este estudio se describe por primera vez la existencia de detrito plutónico en areniscas cretácicas del noroeste de Costa Rica. Los fragmentos de rocas plutónicas son partículas accesorias, comúnmente presentes en las areniscas piroxénicas que sobreyacen al Complejo Ofiolítico de Nicoya. Con base en el análisis modal de los granos del esqueleto, se analizan tres unidades de areniscas turbidíticas y neríticas de las Formaciones Rivas y El Viejo, respectivamente, cuya edad data del Campaniano Tardío-Maastrichtiano. Considerando los componentes primarios, estas areniscas muestran una composición muy similar a aquellas provenientes de arcos magmáticos. Se introducen dos parámetros modales para evaluar las contribuciones plutónicas. Éstos se definen como el índice de granos plutónicos con respecto al total de líticos (Lp+intercrec.QF/Lt) y el índice de piroxeno uralitizado con respecto al piroxeno total (uralPx/Px). Los valores modales del índice Lp+intercrec.QF/Lt indican, que los fragmentos plutónicos constituyen hasta un $9 \%$ del total de líticos. La relación relativamente proporcional entre ambos parámetros sugiere, que el piroxeno uralitizado también se deriva de la erosión de las rocas plutónicas. Las rocas-fuente de detríto plutónico corresponden con rocas intrusivas básicas hasta intermedias: gabros, doleritas y dioritas. Dos componentes en particular - los intercrecimientos micrográficos de cuarzo y albita y el piroxeno uralitizado - son considerados como productos específicos de la erosión cretácica de las rocas intrusivas, principalmente plagiograníticas. Las unidades de areniscas con detríto plutónico registran una erosión incipiente de los niveles inferiores de la secuencia ofiolítica de Costa Rica durante el Campaniano Tardío y Maastrichtiano. En este sentido, los fragmentos plutónicos y los granos de pedernales radiolaríticos asociados pueden ser usados como indicadores paleotectónicos del levantamiento vertical del orógeno de Costa Rica en el Cretácico Tardío. Este evento tectónico se correlaciona con el inicio de la Orogénesis Laramídica. Observaciones de campo evidencian que las rocas intrusivas del Complejo de Nicoya aún hoy día son una fuente miscelánea de sedimento en el noroeste de Costa Rica. 


\section{INTRODUCCIÓN}

Se presenta un estudio petrológico sobre el origen de los componentes plutónicos de las areniscas cretácicas del noroeste de Costa Rica. Los fragmentos de roca de naturaleza plutónica son componentes accesorios importantes de las areniscas, que he descubierto durante el análisis de los modos detríticos. Ellos constituyen entre el $<0.5$ y $9 \%$ de la fracción detrítica. En Costa Rica, el detrito plutónico ha sido identificado principalmente en areniscas miocénicas (Lundberg, 1991). Las areniscas del Complejo de Nicoya o aquellas inmediatamente sobreyacentes al mismo son descritas en la literatura como "basálticas" - producto de la erosión de los flujos y coladas de basaltos (véase Kuypers, 1979 y Lundberg, 1991). Si bien es cierto, que estos materiales volcaniclásticos son predominantes en algunas secuencias, la generalización es errónea. Pues, tanto las areniscas del complejo como las sobreyacentes contienen otros componentes importantes, además de los basálticos. Las wackas volcaniclásticas de la Formación Loma Chumico, por ejemplo, poseen una composición bimodal determinada por componentes básicos y piroclásticos diferenciados (Calvo \& Bolz, 1994). Estudios de procedencia más recientes (Calvo, 1996) demuestran, además, que las areniscas cretácicas suprayacentes contienen una amplia gama de productos de erosión no-basálticos de relevancia, entre los cuales destacan: radiolaritas, pedernales radiolaríticos, detrito carbonatado de aguas someras, alteritas 1 , piroclastos diferenciados y fragmentos de rocas intrusivas. Los objetivos de este estudio son determinar la composición y características del detrito plutónico, su roca-fuente y áreas de procedencia, así como su significado en la evolución tectónica del orógeno de Costa Rica.

\section{MATERIALES Y MÉTODOS}

Se analizaron en total 20 muestras de areniscas en sección delgada. Las muestras provienen de tres unidades de areniscas

1 Partículas sedimentarias compuestas de hidróxidos de Fe, producto de la meteorización en ambiente tropical (Johnsson, 1990). cretácicas, localizadas en distintas áreas de la región antearco del noroeste de Costa Rica (Fig. 1). De cada muestra de roca se preparó una sección delgada perpendicular a la estratificación o laminación. Granulométricamente, se trata de arenitas en sentido textural, es decir, de rocas clásticas cuyo tamaño de grano oscila entre 0.0625 y 2 mm (cf. Pettijohn, 1942). Los análisis y mediciones fueron hechos con un microscopio binocular de luz polarizada Leitz Laborlux 12Pol.

El presente estudio comprende la caracterización microscópica y el análisis cuantitativo del detrito plutónico y demás componentes accesorios. Los tipos de granos y parámetros se definen en el cuadro 2. Los parámetros y valores modales, que se presentan en el cuadro 3, fueron medidos durante el análisis modal de los componentes primarios de las areniscas (Calvo, 1996). El método utilizado para el análisis de los granos del esqueleto es el de Gazzi-Dickinson, que se basa en la técnica del conteo sistemático de puntos. En cada sección se contaron un mínimo de 400 puntos. El reticulado utilizado se ajustó al tamaño de grano para reducir al máximo la influencia de la granulometría sobre los valores modales.

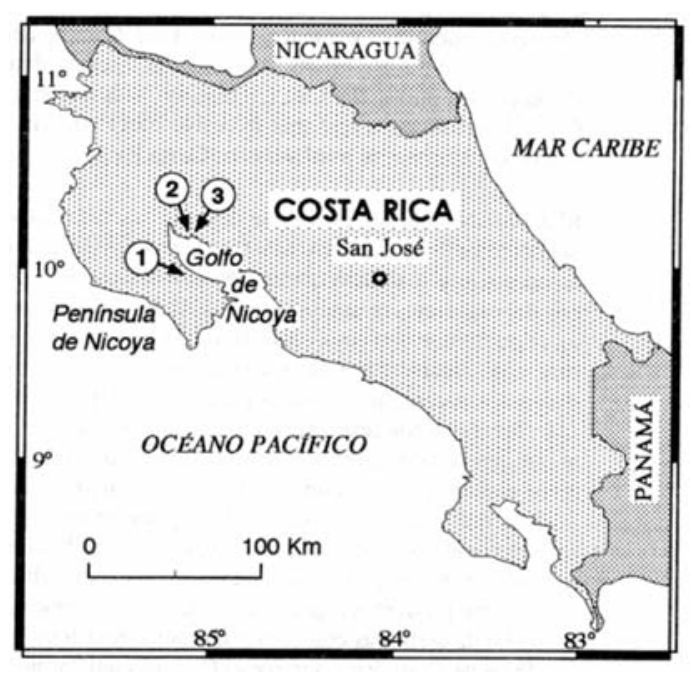

Fig. 1: Localización de tres unidades de areniscas cretácicas que sobreyacen al Complejo de Nicoya en el noroeste de Costa Rica - 1: La Tigra, 2: Quebrada Pilas y 3: Calle Codornices. 


\section{TRES UNIDADES DE ARENISCAS CRETÁCICAS}

Se estudiaron tres unidades de areniscas cretácicas: La Tigra, Quebrada Pilas y Calle Codornices (Fig. 1). Estratigráficamente, pertenencen a la cobertura sedimentaria del Complejo de Nicoya, encontrándose en algunos casos en contacto directo con el mismo (véase Fig. 2). Estas unidades documentan la sedimentación clástica, nerítica y profunda en la región antearco del noroeste de Costa Rica durante el Cretácico Tardío. En el cuadro 1 se resumen sus características principales. Las areniscas de las unidades La Tigra y Quebrada Pilas constituyen dos diferentes litofacies de la Formación Rivas, cuya edad data del Campaniano Tardío-Maastrichtiano Temprano y Maastrichtiano, respectivamente. Desde el punto de vista paleogeográfico, representan la sedimentación turbidítica en distintas áreas de la cuenca de antearco. La secuencia La Tigra se depositó en el talud externo del antearco; sus áreas de procedencia se localizan al noroeste, en la parte oriental de la Península de Nicoya. Por el contrario, la secuencia de Quebrada Pilas se depositó en uno de los taludes occidentales de la plataforma del arco. Áreas inmediatas de procedencia de las areniscas de Quebrada Pilas se encuentran preservadas en la zona del Cerro Barbudal. Las areniscas de Calle Codornices, que afloran al sur de Cerro Barbudal, constituyen una facies nerítica clástica de la Formación El Viejo.

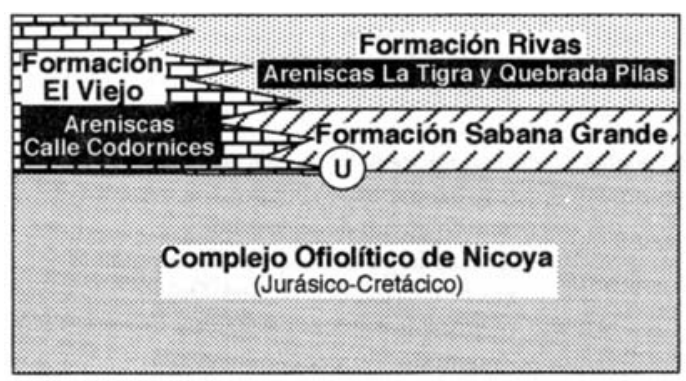

Fig. 2: Posición estratigráfica de las tres unidades de areniscas estudiadas. Cuadro estratigráfico del noroeste de Costa Rica mostrando las formaciones del Campaniano Superior-Maastrichtiano de la Cobertura Sedimentaria del Complejo, modificado de Calvo (1996). U: discordancia del Cretácico Tardío.

\section{Areniscas La Tigra}

Las muestras analizadas son de la base de la secuencia turbidítica que aflora en las cercanías de la localidad de La Tigra (véase Fig. 1). Litofacies similares afloran también en la región de Pilas de Canjel, más al norte. Protti (1981) la describio originalmente como Unidad La Tigra litofacies detrítica. Estratigráficamente, corresponde con un miembro de la Formación Rivas. Es una secuencia turbidítica, granodecreciente, de aproximadamente $150 \mathrm{~m}$ de espesor, generada durante una caída del nivel del mar (Calvo, 1996). Sedimentológicamente, la base de la secuencia se compone de depósitos de rellenos de

Cuadro 1

Características estratigráficas y sedimentológicas de tres unidades de areniscas cretácicas del noroeste de Costa Rica

\begin{tabular}{lccc}
\hline Formación & \multicolumn{2}{c}{ RIVAS } & EL VIEJO \\
\cline { 2 - 4 } Unidad de Areniscas & La Tigra & Quebrada Pilas & Calle Codornices \\
Edad & $\begin{array}{c}\text { Campaniano Superior- } \\
\text { Maastrichtiano Inferior } \\
\text { Sedimentología }\end{array}$ & Maastrichtiano & Campaniano Superior- \\
turbiditas canalizadas & Maastrichtiano \\
Tipo de facies & cuenca de antearco (Cuenca Tempisque) & grainstones \\
Ambiente de & turbiditas canalizadas \\
depositación & de grano grueso & plataforma de arco \\
& talud submarino de & de islas
\end{tabular}


Cuadro 2

Parámetros detríticos y clasificación de los granos del esqueleto

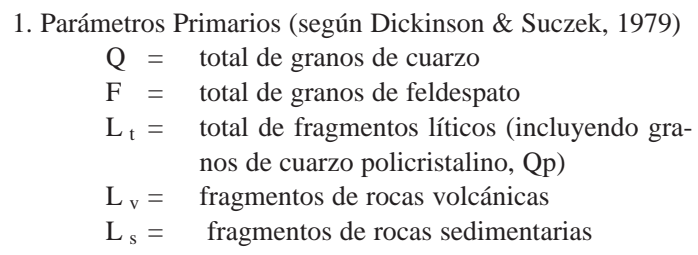

2. Parámetros y Componentes específicos (según Calvo, 1996)

$\mathrm{rC}=$ fragmentos de pedernales radiolaríticos

$\mathrm{L}_{\mathrm{p}}=$ fragmentos holocristalinos compuestos de cuarzo, plagioclasa y piroxeno

intercrec. $\mathrm{QF}=$ intercrecimientos de cuarzo y plagioclasa con textura micrográfica

$\mathrm{Hbl}=$ hornblenda total

$\mathrm{Px}=$ piroxeno total

Biot $=$ biotita total

Índices:

ural Px / Px , donde

ural $\mathrm{Px}=$ piroxeno uralitizado

$\mathrm{L}_{\mathrm{p}}+$ intercrec. $\mathrm{QF} / \mathrm{L}_{\mathrm{t}}$, donde

$\mathrm{L}_{\mathrm{p}}+$ intercrec $. \mathrm{QF}=$ total de fragmentos plutónicos

canal y de flujos de debris arenosos, representados por areniscas de grano grueso hasta guijarrosas con gradación positiva y buena selección del grano. En la parte intermedia y superior de la secuencia dominan, por el contrario, las intercalaciones turbidíticas de arenisca y lutita.

Petrográficamente, las areniscas de la base corresponden con wackas líticas de color gris y rojizo con un contenido de matriz de más de $15 \%$ y en menor grado existen litarenitas y wackas feldespáticas. Se componen de litoclastos, fragmentos biogénicos de aguas someras, cristales detríticos, cemento carbonatado y matriz arcillosa. Los litoclastos son fragmentos de basalto, basalto vesicular, andesita porfirítica, calizas someras y pelágicas, radiolarita, pedernales radiolaríticos y rocas intrusivas (gabro, dolerita y otras). La diagénesis es marina carbonatada. Las impregnaciones y patinas de hidróxidos de hierro, características de algunos componentes, están ligadas con una hematización temprano-diagenética en áreas emergidas.
La asociación de macroforaminíferos, constituida por las especies: Sulcoperculina dickersoni (Palmer), Sulcoperculina globosa de Cizancourt, Pseudorbitoides sp. y Sulcorbitoides pardoi Brönnimann, indica una edad de Campaniano Tardío-Maastrichtiano Temprano. Tomando en cuenta de que se trata de formas neríticas resedimentadas en el ambiente profundo, esta edad se considera como máxima. Las areniscas volcaniclásticas de la parte superior de la secuencia podrían restringuirse al Maastrichtiano.

\section{Areniscas Quebrada Pilas}

Las muestras analizadas provienen de los afloramientos de la Quebrada Pilas y de la cantera Los Almendros, situados en el área del Bajo Tempisque (Fig. 1). Estratigráficamente, estos depósitos clásticos se agrupan en el Miembro San Buenaventura de la Formación Rivas (Calvo, 1996). La secuencia de Quebrada Pilas tiene aproximadamente 100 metros de espesor y está constituida por depósitos de abanico de pie de talud. Litológicamente, las areniscas comprenden tres tipos de facies: wackas feldespáticas, arenitas líticas y packstones de Sulcoperculina. Son arenitas de grano grueso hasta fino con buena selección y fuerte empaquetamiento. Algunas muestras poseen matriz micrítica. Se caracterizan por su color verde, el cual resulta de una autigénesis de minerales verdes de arcilla. Contienen detrito de aguas someras y áreas expuestas. Los primeros son fragmentos de rudistas, gastrópodos, braquiópodos, bryozoos, ostrácodos, equinoideos, corales, macroforaminíferos y algas rojas, así como de inoceramos. La fauna de foraminíferos bentónicos está compuesta de miliólidos, prealveolinidos, pseudorbitoideos, lepidorbitoideos y sulcoperculinoideos. Restos de plantas y madera perforada por epibiontes (Terenidos?) y alteritas constituyen el detrito de las áreas emergidas.

Las areniscas contienen una rica microfauna de mezcla, compuesta de foraminíferos planctónicos y macroforaminíferos del Maastrichtiano. La asociación de Gansserina gansseri (Bolli) y Orbitocyclina minima (H. Douvillé), dos especies guías que se restringuen al Maastrichtiano, es 
muy característica de las areniscas de la Quebrada Pilas. Algunos niveles de la secuencia se caracterizan además por la asociación de macroforaminíferos Sulcoperculina-Orbitocyclina. Los estudios detallados de la macrofauna de los depósitos del Tajo Los Almendros, realizados por Fischer \& Aguilar (1994), evidencian del mismo modo una edad maastrichtiana.

\section{Areniscas Calle Codornices}

Las areniscas conforman una secuencia clástica de pocos metros de espesor, que aflora en la Calle Codornices, camino a Manzanillo (Fig. 1). En términos de "estratigrafía secuencial", se trata de una secuencia nerítica transgresiva, desarrollada sobre áreas cretácicas emergidas. Paleogeográficamente, se sitúa en el margen occidental de la plataforma del arco de islas, siendo separada del ambiente profundo por el escarpe de Barbudal. Litológicamente, se trata de arenitas híbridas (bioarenitas), arenitas líticas y feldespáticas con relativa buena selección del grano. El empaquetamiento es pobre. Texturas de tipo "grainstone" y "packstone" con muy poca matriz son características. El contenido de fragmentos carbonatados, biogénicos y no biogénicos, alcanza hasta el 50\% del total de granos del esqueleto. Los no biogénicos comprenden cortoides, ooides ferruginosos e intraclastos de calizas micríticas. Los biogénicos son fragmentos de algas calcáreas, principalmente coralinacéas, equinoideos, rudistas, corales, bryozoos, macroforaminíferos, foraminíferos incrustantes y miliólidos, así como restos de plantas. Fragmentos de tobas vítreas, compuestas de esquirlas delgadas de vidrio incoloro y fragmentos de basalto muy alterado (alteritas) son frecuentes. La mayoría de las muestras exhibe una diagénesis carbonatada de ambiente marino poco profundo y una diagénesis temprana hematítica. La última consiste de una impregnación parcial hasta total de los componentes con hidróxidos de hierro. La hematita está representada por películas superficiales, ooides ferruginosos y fragmentos biogénicos hematitizados. La poca matriz micrítica contiene además granos detríticos de hematita. La petrofacies de Calle
Codornices es muy similar a la de la unidad La Tigra, concretamente a la de las areniscas de la base de la secuencia.

La presencia de las especies de macroforaminíferos Sulcoperculina globosa de Cizancourt, Sulcoperculina sp. y Pseudorbitoides sp. atestiguan una edad de Campaniano Tardío-Maastrichtiano Temprano.

\section{PETROFACIES}

A continuación se presenta la caracterización petrográfica del detrito plutónico y el análisis cuantitativo de los modos detríticos específicos, con énfasis en el material plutónico.

\section{Detrito plutónico}

El detrito de origen plutónico en las areniscas cretácicas de la región de antearco comprende una gama de fragmentos líticos holocristalinos y cristales sueltos. Entre ellos destacan los fragmentos cuarzo-feldespáticos con textura micrográfica, cuarzos policristalinos, y en menor proporción fragmentos holocristalinos compuestos de cuarzo, plagioclasa, piroxeno, hornblenda (secundaria?) y minerales opacos, así como cristales detríticos de piroxeno, plagioclasa y cuarzo. Los primeros se componen de intercrecimientos de cuarzo y plagioclasa sódica (albita). Petrológicamente, los intercrecimientos micrográficos son un indicio de la presencia de agua durante la cristalización eutéctica (Tröger, 1967). Bajo el microscópio se puede identificar fácilmente el intercrecimiento de ambas especies minerales (Figs. 3 y 5). En luz polarizada, muestran la típica textura micrográfica, la cual se reconoce por la marcada diferencia del ángulo de extinción entre ambos (Fig. 3). En luz natural, los enclaves albíticos muestran un aspecto turbio, un poco opaco, debido a la alteración a minerales de arcilla, mientras que el cuarzo permanece inalterado. En las areniscas de Calle Codornices, las zonas albíticas alteradas presentan una ligera pigmentación rojiza 
Detrito de rocas intrusivas del Complejo de Nicoya en areniscas cretácicas del noroeste de Costa Rica

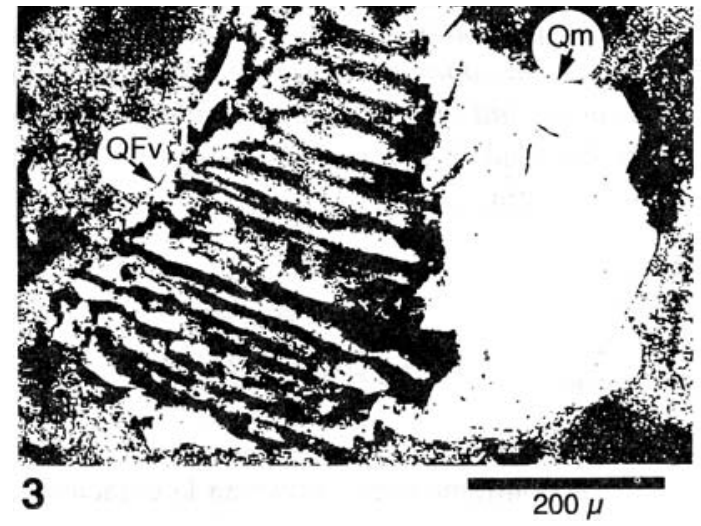

Fig. 3: Fragmento lítico de origen plutónico compuesto de cuarzo monocristalino $(\mathrm{Qm})$ e intercrecimientos micrográficos de cuarzo y albita (QFv). Arenisca de Calle Codornices, Formación El Viejo. Muestra BB-14/4. Nicoles cruzados.

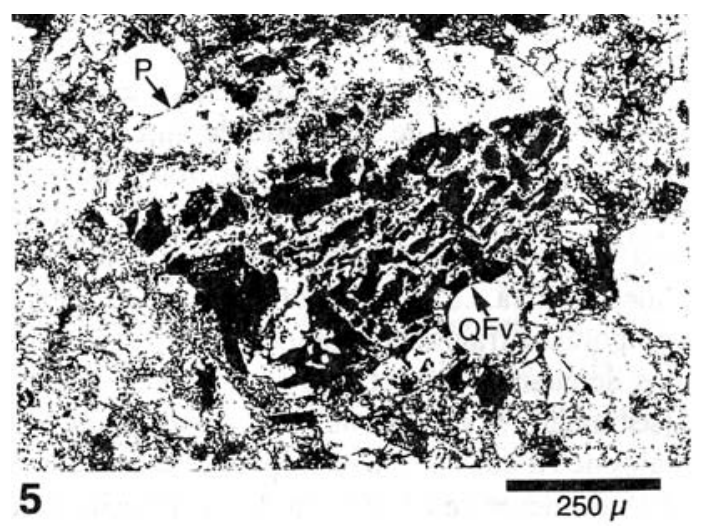

Fig. 5: Fragmento lítico compuesto de plagioclasa alterada (P) e intercrecimientos cuarzo-albíticos de textura micrográfica $(\mathrm{QFv})$. Arenisca de Quebrada Pilas, Formación Rivas. Muestra BB-4/6a. Nicoles cruzados.

muy característica, que se debe a la presencia de óxidos de Fe y Ti (de Jamet, 1980). Granos cristalinos con textura micrográfica por intercrecimiento son considerados como el tipo de fragmento lítico de origen plutónico por excelencia (Füchtbauer, 1988).

Los fragmentos líticos de cuarzo policristalino están formados por pocos cristales de

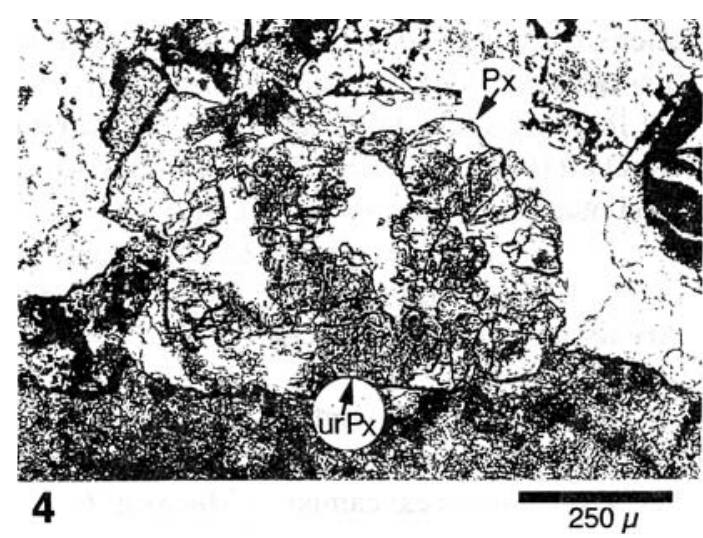

Fig. 4: Cristal detrítico de piroxeno uralitizado (urPx) mostrando núcleos sanos de piroxeno (Px). Arenisca de Calle Codornices, Formación El Viejo. Muestra BB-14/4. Nicoles cruzados.

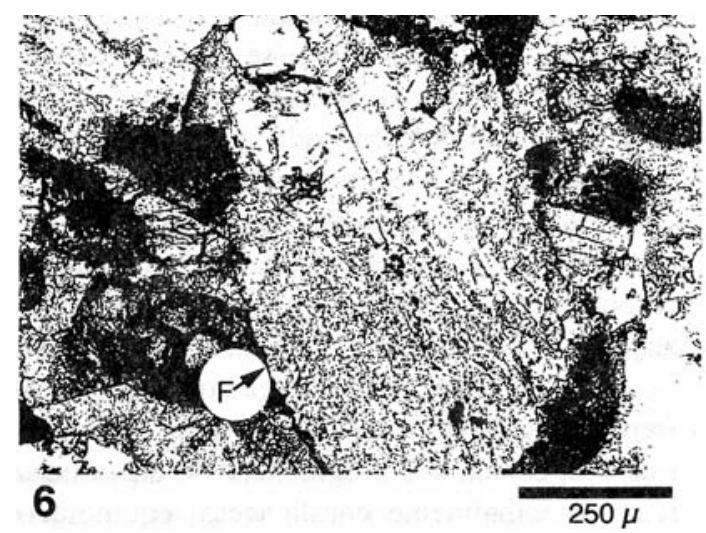

Fig. 6: Fragmento de feldespato (F) con impregnaciones superficiales de hematita. Se trata de un fragmento de cristal compuesto de zonas anortíticas alteradas a calcita y arcillas y zonas albíticas sanas. Areniscas de Calle Codornices, Formación El Viejo. Muestra BB-14/5. Nicoles paralelos.

cuarzo de grano relativamente grueso. Los contactos entre los individuos son regulares, raramente suturados. Algunos poseen texturas micrográficas. También ocurren fragmentos holocristalinos con piroxeno uralitizado y plagioclasa polisintética. La mayoría tiene una textura hipidiomórfica granular. La textura subofítica aparece en los fragmentos compuestos 
principalmente de plagioclasa y clinopiroxeno. En una muestra de arenisca de Calle Codornices se identificaron, además, dos fragmentos de roca holocristalinos con cristales de hornblenda. Un tipo particular de grano son los fragmentos de feldespatos con intercrecimientos albíticoanortíticos de origen intrusivo (véase Fig. 6). Intimamente asociado con los fragmentos líticos de origen plutónico se encuentra piroxeno detrítico, en forma de cristales sueltos y también cristales incluídos en fragmentos de roca holocristalina. Un número significativo de cristales muestra una uralitización parcial (Fig. 4).

\section{Análisis Modal}

En términos de sus componentes primarios $(\mathrm{Q}, \mathrm{F}$ y Lt), las areniscas cretácicas de las formaciones Rivas y El Viejo poseen una composición similar a aquellas procedentes de arcos magmáticos (Calvo, 1996). En este estudio se hace enfásis en los índices y modos detríticos de procedencia plutónica (Cuadro 3). Los valores cuantitativos de las contribuciones de material plutónico calculados aquí, deben ser considerados como valores mínimos, es decir, los valores totales pueden ser en realidad mucho mayores.

\section{Cuadro 3}

Valores modales de los parámetros y componentes específicos (1) de veinte muestras de areniscas cretácicas de las Formaciones El Viejo y Rivas del noroeste de Costa Rica

\begin{tabular}{|c|c|c|c|c|c|c|c|c|}
\hline \multirow[b]{2}{*}{$\begin{array}{l}\text { Muestra } \\
\text { No. }\end{array}$} & \multicolumn{3}{|c|}{ Fragmentos Líticos (2) } & \multicolumn{3}{|c|}{ Cristales Máficos $(2,3)$} & \multirow{2}{*}{$\begin{array}{l}\text { Indices } \\
\text { Lp+inter- } \\
\text { crec.QF/Lt }\end{array}$} & \multirow[b]{2}{*}{ uralPx/Px } \\
\hline & $\mathrm{Lv}$ & $\begin{array}{l}\text { Lp+inter- } \\
\text { crec.QF }\end{array}$ & $\mathrm{rC}+\mathrm{Ls}$ & $\mathrm{Px}$ & $\mathrm{Hbl}$ & Biot & & \\
\hline \multicolumn{9}{|c|}{ Arenicas Calle Codornices } \\
\hline BB-14/1 & 81 & 6 & 13 & 96 & 2 & 2 & .055 & .075 \\
\hline BB-14/2 & 81 & 5 & 14 & 100 & 0 & 0 & .044 & .020 \\
\hline BB-14/4 & 80 & 5 & 15 & 100 & 0 & 0 & .050 & .050 \\
\hline BB-14/4a & 86 & 6 & 8 & 100 & 0 & 0 & .051 & .100 \\
\hline BB-14/7 & 78 & 9 & 13 & 100 & 0 & 0 & .090 & .180 \\
\hline \multicolumn{9}{|c|}{ Areniscas La Tigra } \\
\hline LT-1/1 & 86 & 8 & 6 & 100 & 0 & 0 & .082 & .216 \\
\hline LT-1/4 & 87 & 5 & 8 & 97 & 0 & 3 & .056 & .133 \\
\hline LT-1/5 & 80 & 6 & 14 & 100 & 0 & 0 & .060 & .077 \\
\hline LT- $2 / 2$ & 94 & 1 & 5 & 2 & 79 & 0 & .010 & 0 \\
\hline LT-2/6 & 83 & 3 & 14 & 100 & 0 & 0 & .033 & 0 \\
\hline LT-4/1 & 83 & $<0.5$ & 17 & 67 & 33 & 0 & .002 & 0 \\
\hline LT-4/1a & 89 & 1 & 10 & 100 & 0 & 0 & .007 & 0 \\
\hline \multicolumn{9}{|c|}{ Areniscas Quebrada Pilas } \\
\hline BB-4/1b & 43 & 3 & 54 & 33 & 62 & 5 & .023 & 0 \\
\hline BB- $4 / 2 b$ & 49 & 2 & 49 & 53 & 47 & 0 & .010 & 0 \\
\hline BB- $4 / 5 b$ & 56 & 0 & 44 & 33 & 67 & 0 & 0 & 0 \\
\hline BB-4/1a & 49 & $<0.5$ & 51 & 40 & 57 & 3 & .003 & 0 \\
\hline BB-4/2a & 42 & $<0.5$ & 58 & 63 & 37 & 0 & .006 & 0 \\
\hline BB-4/5a & 47 & 1 & 52 & 31 & 54 & 15 & .012 & 0 \\
\hline BB-4/6b & 70 & 0 & 30 & 5 & 93 & 2 & 0 & 0 \\
\hline BB-4/6a & 56 & 2 & 42 & 13 & 87 & 0 & .020 & 0 \\
\hline
\end{tabular}

(1) los valores modales de los componentes primarios se encuentran en Calvo (1996)

(2) valores porcentuales para la representación gráfica en diagramas triangulares

(3) considerados unicamente cristales sueltos 
Posibles fuentes de error son los fragmentos monocristalinos de cuarzo y plagioclasa. En la mayoría de los casos, estos componentes no presentan caracteres particulares que permitan discriminar con certeza su naturaleza plutónica o volcánica. Por esta razón no son tomados en cuenta, no obstante, introducen un error en la cuantificación de las contribuciones totales. Una excepción son los mencionados fragmentos de feldespato de la figura 6 , cuyas texturas de intercrecimiento confirman su origen intrusivo.

\section{Parámetros detríticos}

La composición detrítica de las areniscas se puede también definir en función de sus accesorios y componentes específicos. A continuación se describe la fracción detrítica en términos de sus fragmentos líticos y de la fracción de cristales máficos. El diagrama triangular (Lp+intercrec.QF) Lv(rC+Ls) de la figura 7 muestra la representación gráfica de los valores modales de tres tipos determinados de fragmentos líticos, a saber: fragmentos de rocas plutónicas (Lp+intercrec.QF), volcánicas (Lv) y sedimentarias (rC+Ls). En los fragmentos sedimentarios se incluyen los pedernales radiolaríticos. En este diagrama, se puede reconocer la predominancia de los fragmentos volcánicos, que caracteriza a la mayoría de las muestras analizadas. Las areniscas de la Formación Rivas exhiben, sin embargo, tendencias muy divergentes. Las areniscas La Tigra muestran valores considerables de detrito plutónico y volcánico, muy similares a los de las areniscas neríticas de Calle Codornices. En ambos casos, se observa la influencia significativa de rocas de origen plutónico. Por el contrario, en las areniscas de Quebrada Pilas destacan los valores extraordinariamente altos de fragmentos de rocas sedimentarias. En algunas muestras, éstos predominan inclusive sobre los valores de fragmentos volcánicos. La predominancia de granos de pedernales radiolaríticos en estas areniscas se interpretada como una procedencia de un prisma de accreción obducido, compuesto de materiales radiolaríticos, los cuales están representados hoy día por las rocas de la Formación Punta Conchal
(Calvo, 1996). En la unidad Quebrada Pilas, el detríto plutónico aparece muy diseminado.

El diagrama Biot-Hbl-Px de la figura 7 muestra también los valores de la fracción detrítica de cristales máficos sueltos, compuesta de biotita (Biot), hornblenda ( $\mathrm{Hbl}$ ) y piroxeno (Px). Según la fracción de cristales máficos se pueden diferenciar dos tipos principales de areniscas: piroxénicas y piroxeno-hornbléndicas. La mayoría de las muestras contiene clinopiroxeno y hornblenda verde. Las areniscas de La Tigra son predominantemente piroxénicas, mientras que en las de Quebrada Pilas domina la hornblenda. Los packstones de Sulcoperculina son un caso especial; debido a sus valores extraordinariamente altos de hornblenda, que constituyen entre 87 y 93\% de dicha fracción, se consideran como hornbléndicos. Las areniscas más volcaniclásticas de la Tigra contienen también mucha hornblenda, llegando una muestra a alcanzar valores similares a los de las packstones de Sulcoperculina. Por el contrario, las areniscas de Calle Codornices son piroxénicas. La mayoría de las muestras son muy ricas en clinopiroxeno, frecuentemente uralitizado y la hornblenda está casi ausente. El enriquecimiento en piroxeno está en relación directa con valores significativos de fragmentos plutónicos (Fig. 7). La biotita es muy escaza en casi todas las muestras, únicamente en algunas areniscas de Quebrada Pilas y en una de Calle Codornices se identificaron cristales diseminados.

\section{Relación entre el piroxeno y los líticos de origen plutónico}

La figura 8 muestra los índices de Lp+intercrec.QF/Lt contra uralPx/Px. En la fracción arenosa de las muestras analizadas destaca una relación muy estrecha entre el contenido de fragmentos plutónicos y el de cristales de piroxeno detrítico. Esta relación se manifiesta de forma relativamente proporcional en las areniscas de Calle Codornices y La Tigra, que contienen más de un $4 \%$ de líticos plutónicos. En estas areniscas, se observa un aumento del contenido de fragmentos de cristales de piroxeno, en especial de piroxeno uralitizado, al aumentar el contenido de 

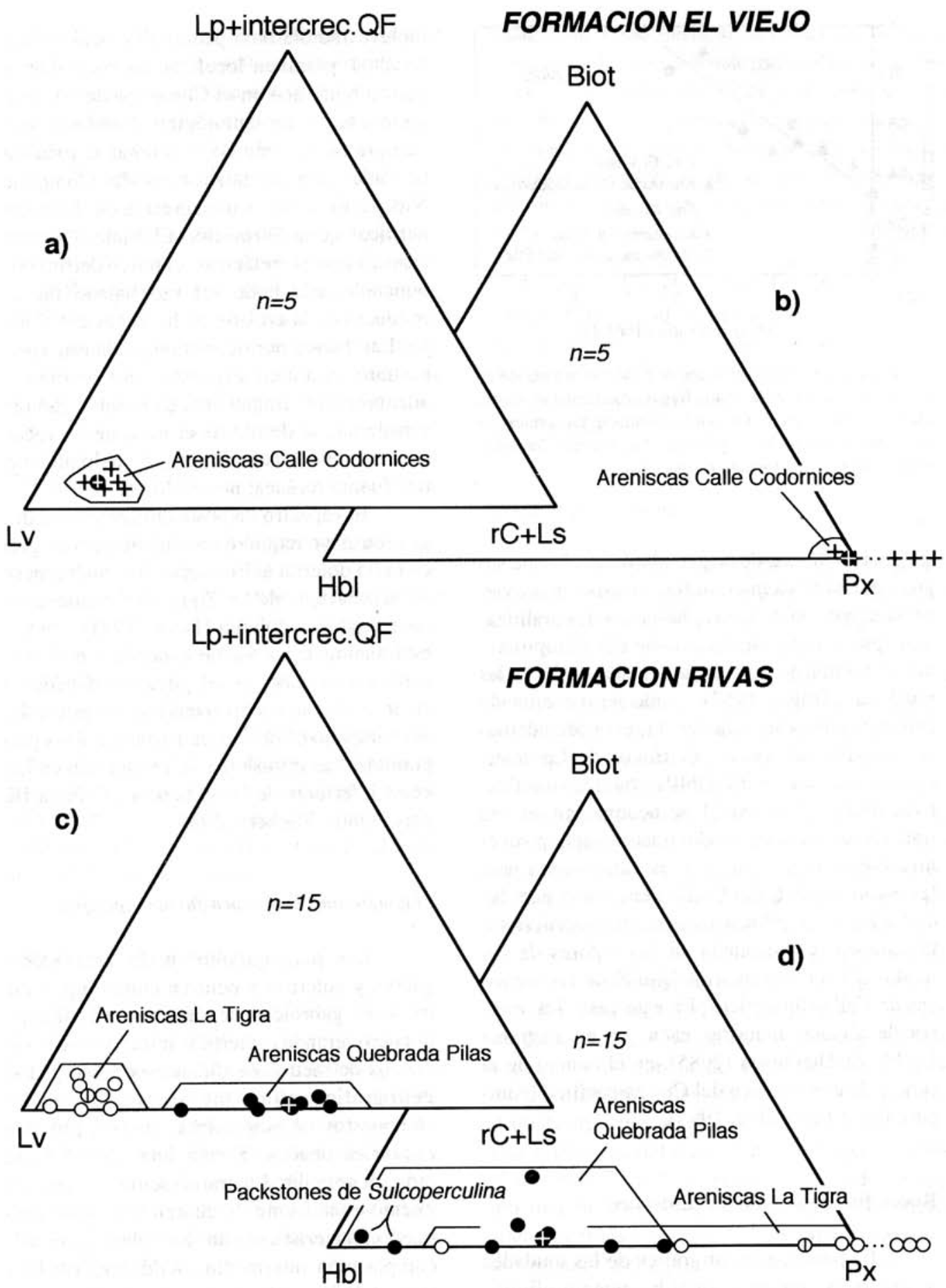

Fig. 7: Diagramas triangulares de los componentes líticos y de la fracción detrítica de cristales máficos sueltos de veinte muestras de areniscas de las Formaciones Rivas y El Viejo (Campaniano Superior-Maastriano). Se incluyen los valores medios. $\mathrm{n}=$ número de muestras. 


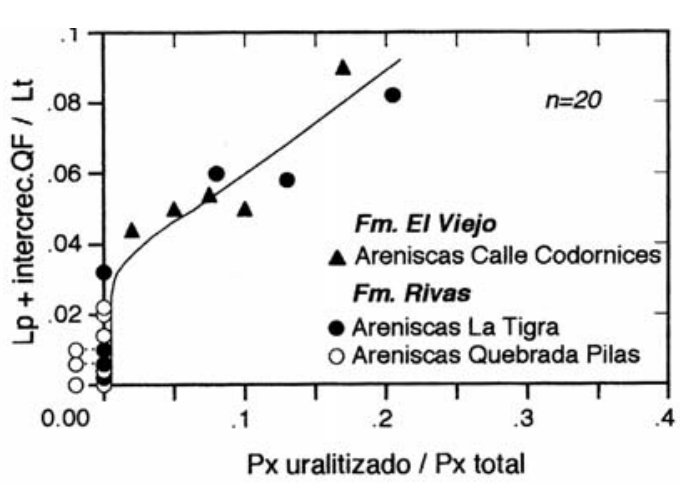

Fig. 8: La ocurrencia de cristales de piroxeno uralitizado en relación con el aumento de los fragmentos líticos de origen plutónico (Lp+intercrec.QF) en las areniscas piroxénicas de las Formaciones El Viejo y Rivas (Campaniano SuperiorMaastrichtiano). $\mathrm{n}=$ número de muestras.

fragmentos líticos de origen plutónico, lo que sugiere que el piroxeno uralitizado también proviene de la erosión de rocas plutónicas. La uralitización, proceso de transformación del clinopiroxeno en hornblenda, es característica de la facies plutónica (Tröger, 1967). Como he mencionado anteriormente, esta relación se reconoce además al comparar los valores detríticos de Lp+intercrec.QF con los de BiotHblPx: valores significativos de Lp+intercrec.QF se acompañan de una fracción de cristales predominantemente piroxénica (véase Fig. 7), lo cual es válido tanto para las areniscas de Calle Codornices como para las de La Tigra. La influencia de rocas plutónicas está también documentada en los valores de los modos detríticos primarios QmPK de las areniscas de Calle Codornices. En este caso, los valores de algunas muestras caen, en el diagrama QmPK de Dickinson (1985), en el campo de la serie vulcanoplutónica del Circumpacífico (compare Fig. 87 en Calvo, 1996).

\section{Rocas-fuente de detrito plutónico}

La posición estratigráfica de las unidades de areniscas con respecto al basamento ofiolítico (véase Fig. 2) y la composición del detrito asociado con los fragmentos plutónicos, que incluye radiolaritas, pedernales radiolaríticos y basaltos, permiten localizar las rocas-fuente de detrito plutónico en el Complejo de Nicoya. Un argumento sedimentológico concluyente, que permite igualmente correlacionar la roca-fuente plutónica con las intrusiones del Complejo de Nicoya, es la facies transgresiva de las areniscas neríticas de la Formación El Viejo. Durante las transgresiones cretácicas, el único detrito no carbonatado, que pudo ser retrabajado fue aquel producto de la erosión de las rocas del Complejo. Las facies neríticas transgredieron sobre el sustrato ofiolítico expuesto, incorporando así, además de los fragmentos de basalto, radiolarita y pedernal, el detrito de erosión de las rocas intrusivas. Esto hace descartar, ineludiblemente, una fuente foránea, no ofiolítica.

El espectro de productos detríticos de origen intrusivo requiere una fuente de roca gabroica hasta dolerítica. En efecto, los conglomerados de la secuencia de La Tigra, que contienen clastos de gabro y dolerita (Protti, 1981), confirman esta analogía. La fuente específica de los fragmentos plutónicos y del piroxeno detrítico asociado se atribuye a las rocas intrusivas cretácicas del complejo ofiolítico, en particular a los plagiogranítos. Las intrusiones se encuentran en los niveles inferiores de la secuencia ofiolítica (Kuypers, 1980; Wildberg, 1987).

\section{Plagiogranitos como roca-fuente específica}

Los plagiogranitos están asociados con gabros y doleritas y ocurren como diques en intrusiones gabroicas, de varios metros de espesor o como grandes cuerpos intrusivos de varios cientos de metros de diámetro (Wilberg, 1987). Petrográficamente, los plagiogranitos están compuestos de plagioclasa, cuarzo, piroxeno y minerales opacos. Tienen una textura hipidiomórfica granular. La uralitización y el intercrecimiento cuneiforme de cuarzo y plagioclasa son muy característicos de los plagiogranitos de composición intermedia (Wildberg, 1984). Gabros, doleritas y dioritas pueden contener este tipo de fases minerales (véase Kussmaul, 1980). Sin embargo, concentraciones detríticas tan 
altas, de hasta $9 \%$ del total de líticos, como se encuentran en la facies nerítica, precisan de una fuente más específica, que contenga concentraciones originales significativas, mas que accesorias. Este es el caso de los plagiogranitos. Kuijpers (1979) señala la abundancia de intercrecimientos micrográficos de cuarzo y albita en algunos plagiogranitos del complejo, por ejemplo en aquellos de Playa Ocotal, en la costa noroeste de la Península de Nicoya. El bajo contenido de feldespato potásico y de biotita en la fracción arenosa hace excluir las rocas graníticas como una posible roca-fuente. La predominancia de plagioclasa sódica y la relación entre el piroxeno uralitizado y los intercrecimientos de cuarzo y albita en la fracción detrítica sugieren una roca-fuente plutónica básica o intermedia, preferentemente plagiogranítica.

Rocas plutónicas de composición intermedia y diferenciada, asociadas con el complejo ofiolítico, se encuentran en otras regiones del Sur de América Central. Por ejemplo en Panamá, específicamente en la Península de Azuero, afloran rocas plutónicas que también intruyen la secuencia ofilítica de antearco. Se trata de rocas plutónicas cuarzo-dioríticas del Cretácico Tardío. Según Schweikert (1997), su composición mineralógica consiste de plagioclasa, clinopiroxeno, anfibol y cuarzo. Éste último aparece en intercrecimiento micrográfico con plagioclasa. El clinopiroxeno uralitizado es común.

\section{Origen de las rocas plutónicas}

En el Complejo de Nicoya, Wildberg (1987) reconoce dos tipos de rocas plagiograníticas, que denomina como plagiogranitos de nivel bajo y de nivel alto, según su posición en la secuencia ofilítica. Los plagiogranitos de nivel bajo los identificó en la Península de Santa Elena y tienen un origen intraoceánico de arco de islas. Los de nivel alto, por el contrario, son de origen oceánico. Éstos se localizan en la costa noroeste de la Península de Nicoya.

Los cuerpos plagiograníticos de la region oriental de la península aún no han sido estudiados; de ahí provienen algunas de las areniscas analizadas. Cabe destacar la presencia de rocas plutónicas de arco calcoalcalino diferenciado en el sur de la península. Estas rocas poseen unas características geoquímicas muy similares a la de las intrusiones cuarzo-dioríticas del Cretácico Tardío de la Península de Azuero. Estudios geoquímicos afirman que se trata en ambos casos de rocas diferenciadas de arco de islas maduro (Wildberg, 1987; Schweikert, 1997).

Por esta razón, se debe considerar la posibilidad de que el detrito plutónico de las areniscas cretácicas sea, en parte, un producto de la denudación de las rocas intrusivas calcoalcalinas del arco de islas cretácico del Sur de América Central.

\section{Áreas de procedencia}

La distribución geográfica de las areniscas estudiadas muestra la existencia de áreas cretácicas de procedencia de material plutónico muy distintas. El tamaño de grano, por otro lado, exige una área fuente relativamente cercana al sitio de depositación. Las areniscas de la unidad La Tigra, en la región oriental de la península, son en ese sentido un caso ejemplar, pues en esta zona afloran muchos cuerpos intrusivos, entre ellos también plagiograníticos. Protti (1981) describe un filón-manto plagiogranítico en la Quebrada Cuajiniquil, a pocos kilómetros de la localidad de La Tigra, donde aflora la secuencia turbidítica analizada. Estas rocas intrusivas constituyen indudablemente una fuente potencial del material cretácico de las areniscas. Por otra parte, el detrito plutónico de las unidades Calle Codornices y Quebrada Pilas sugiere la existencia de áreas de procedencia mucha más orientales, situadas en la región del Bajo Tempisque, al norte del Golfo de Nicoya. Los intrusivos del Cerro Barbudal, que afloran al norte de Calle Codornices se consideran como una fuente potencial. Las calizas neríticas sobreyacentes contienen fragmentos diseminados de naturaleza plutónica. En efecto, las mismas rocas intrusivas contienen fases minerales accesorias con intercrecimientos de cuarzo y albita (Calvo, 1996). 


\section{Dispersión del detrito plutónico}

La sedimentología de las facies de areniscas analizadas documenta una marcada dispersión del detrito intrusivo en el ambiento marino. La dispersión está determinada por las áreas de procedencia y las oscilaciones del nivel del mar. La figura 9 presenta un modelo hipotético de dispersión para las facies cretácicas en función de las oscilaciones del mar. En las litofacies neríticas de Calle Codornices, el detrito plutónico fue incorporado por medio de una transgresión marina sobre áreas emergidas. Es decir, por la inundación de áreas de procedencia, donde fueron expuestos los niveles inferiores del Complejo de Nicoya. De este modo, el material intrusivo aparece concentrado en las facies basales del cortejo transgresivo, directamente sobre las discordancias del Campaniano Tardío y Maastrichtiano, encontrándose no muy lejos de la roca-fuente. Esta situación se aprecia hoy día en el Cerro Barbudal. Ahí, las facies arrecifales transgresivas crecieron directamente sobre sustrato basáltico, asociado lateralmente con intrusiones doleríticas. El detrito no-carbonatado de estas facies contiene fragmentos de roca de origen intrusivo. En las litofacies de talud, por el contrario, el detrito fue transportado al ambiente profundo por corrientes de turbidez y flujos arenosos durante la caída del nivel del mar. El material aparece así distribuido en distintos niveles de la secuencia, principalmente en areniscas canalizadas de grano medio a grueso. La distribución y diseminación del detrito por corrientes de turbidez parece ser más efectiva que en el ambiente nerítico. Esto podría explicar la relativa concentración de detrito plutónico en la facies nerítica, en comparación con la facies profunda, donde el detrito aparece mucho más diseminado (compárese Fig. 9).

\section{Significado tectónico}

A diferencia de las areniscas basálticas que resultaron de la erosión de los flujos de basalto y de lavas en almohadilla, el detrito plutónico de las areniscas cretácicas documenta una erosión profusa, que alcanzó los niveles

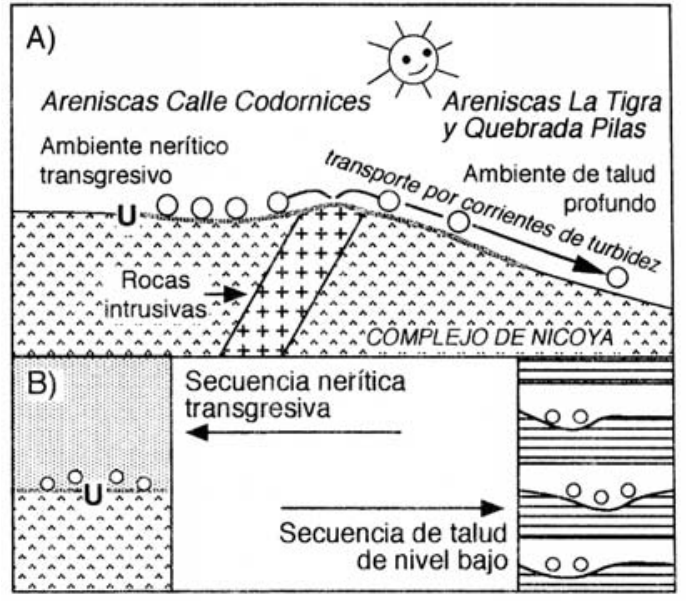

Fig. 9: Modelo de dispersión del detrito plutónico durante las variaciones del nivel del mar en el Cretácico Tardío (A). Distribución del detrito en las secuencias nerítica de Calle Codornices y turbidíticas de La Tigra y Quebrada Pilas (B). U: superficie de erosión de las áreas expuestas, discordancia del Cretácico Superior.

inferiores, de la secuencia ofiolítica de Costa Rica (véase Fig. 10). En la evolución del orógeno de Costa Rica, esto significa, que en el Cretácico existieron períodos largos de exposición y denudación durante la formación del arco de islas. De acuerdo con las edades de las areniscas, la erosión tuvo lugar en el Campaniano Tardío y Maastrichtiano. Esto implica, por consiguiente, que la edad mínima de las intrusiones del Complejo de Nicoya es Campaniano. Estudios geoquímicos de estas rocas permiten considerar la posibilidad de que el detrito plutónico sea el resultado, al menos en parte de la erosión de rocas plutónicas del arco de islas del Cretácico, que intruyeron la secuencia ofiolítica. Según Calvo \& Bolz (1994), este arco se encontraba activo desde el Albiano.

Otro tipo específico de componente detrítico identificado en las areniscas cretácicas, que de igual forma documenta la erosión fuerte del Complejo de Nicoya son los pedernales radiolaríticos (Calvo, 1996). Al igual que los arrecifes y plataformas carbonatadas del Senoniano Superior, que crecieron sobre sustratos ultramáficos y volcánicos (Calvo, 1987), el detrito plutónico y los fragmentos redondeados de pedernales radiolaríticos 
se interpretan como indicadores paleotectónicos del levantamiento drástico del orógeno de Costa Rica. Ambos componentes pueden ser considerados como marcadores detríticos de la inconformidad del Cretácico Superior - la discordancia cretácica más importante del Sur de América Central. Este levantamiento tectónico en el Cretácico Tardío se correlaciona con el inicio de la Orogénesis Laramídica (Calvo, 1996).

\section{Perfil de erosión cretácico}

La figura 10 muestra el perfil de erosión hipotético a través de la secuencia ofiolítica en el Cretácico Tardío. Tomando en cuenta la asociación más antigua de macroforaminíferos pseudorbitoideos de las areniscas, se asume una edad de Campaniano Tardío. Como se deduce a partir del espectro detrítico, la denudación afectó tanto los niveles superiores de la secuencia, como los inferiores, donde se encuentran las intrusiones y los plagiogranitos. Por otra parte, el espectro de productos de erosión, que comprende además fragmentos de basalto, radiolaritas, taquilitas y alteritas permite deducir una asociación cretácica de rocas-fuente ofiolítica muy similar a la que actualmente conforma la región de antearco de Costa Rica (véase Fig. 11). La existencia de las áreas emergidas está documentada por fragmentos piroclásticos vesiculares y de basalto muy meteorizado (alteritas) y en especial por fragmentos de madera y restos de plantas, que aparecen en muchas de las areniscas analizadas.

Estudios de procedencia preliminares de las areniscas paleógenas y neógenas, que sobreyacen al Complejo de Nicoya, revelan del mismo modo la existencia de detrito de rocas intrusivas en sedimentos más jóvenes. También en las areniscas terciarias de la región trasarco de Costa Rica y Panamá, se observan fragmentos líticos de origen plutónico. Wozasek (1997) describe en las areniscas del Río Changuinola, en el noroeste de Panamá, fragmentos de

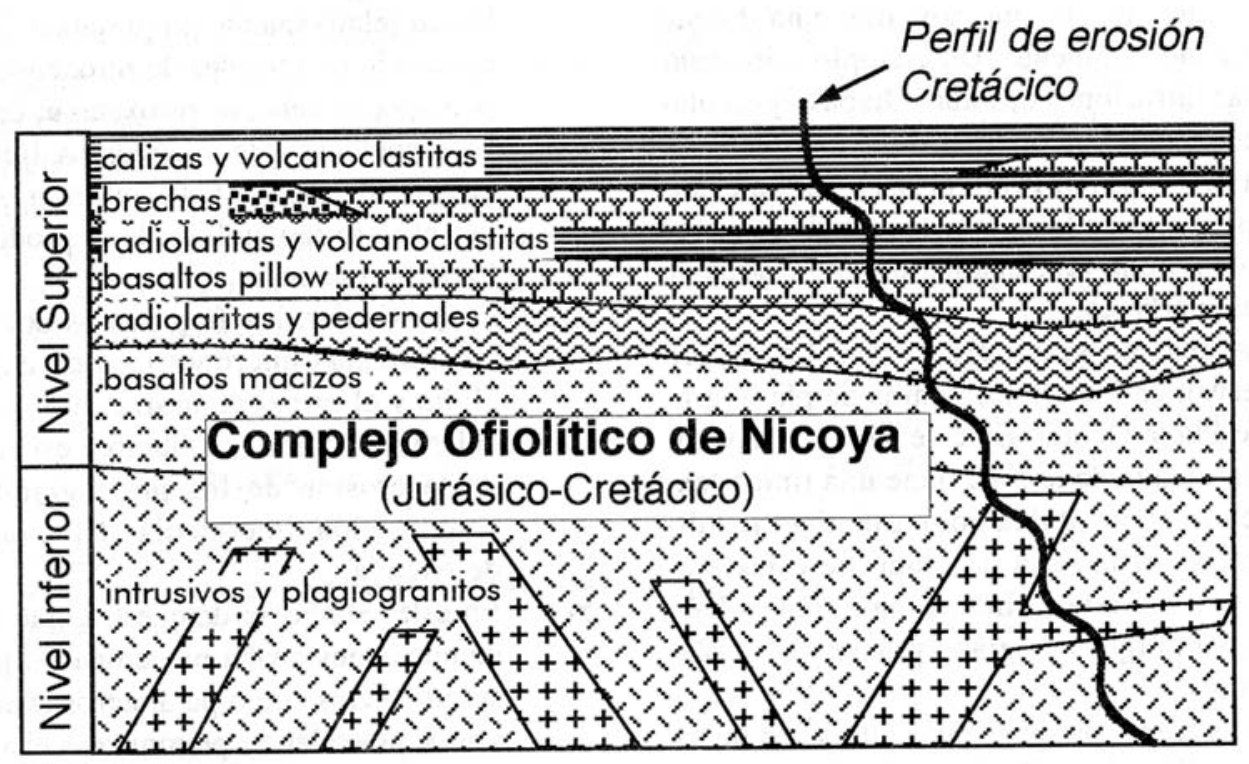

Fig. 10: Perfil de erosión de la secuencia ofiolítica del Complejo de Nicoya durante el Cretácico Tardío (aprox. a los 75 Ma), deducido a apartir del espectro detrítico de las areniscas sobreyacentes de las Formaciones Rivas y El Viejo (Campaniano TardíoMaastrichtiano). La erosión alcanzó los niveles inferiores de la secuencia ofiolítica. Sin escala. 


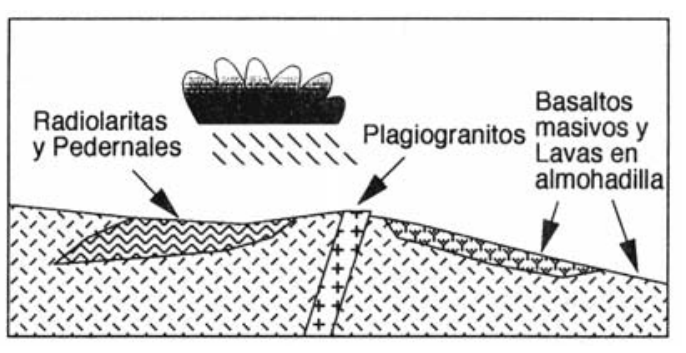

Fig. 11: Modelo de procedencia del Complejo de Nicoya mostrando una asociación de rocas típica del Campaniano Superior-Maastrichtiano, muy similar a la que hoy día aflora en la región de antearco (según Calvo, 1996).

diorita diseminados, que presentan intercrecimientos micrográficos de cuarzo y plagioclasa. La roca-fuente en este caso son cuerpos intrusivos granodioríticos del arco interno.

\section{La erosión de los intrusivos hoy en día}

Observaciones de campo indican además, que las rocas intrusivas del Complejo de Nicoya constituyen aún hoy día, una fuente particular de sedimento. Un ejemplo importante son las intrusiones de gabro-diabasa y de plagiogranitos del área oriental de la Península de Nicoya descritas por Protti (1981). Según el autor, el producto de la meteorización de estas rocas es una arena feldespática de grano grueso, muy característica.

Arenas de grano grueso y color blanco se observan en los afloramientos de plagiogranitos de Playa Ocotal. En este caso, la superficie meteorizada de la roca tiene una típica textura arenosa, constituída por partículas cristalinas sueltas. El tamaño de grano de estas areniscas parece estar directamente controlado por la textura ígnea de grano grueso de los plagiogranitos.

Las arenas producto de la alteración de rocas más básicas, como los gabros, son en general mucho más oscuras y sobretodo ricas en magnetita. Estas concentraciones altas de magnetita detrítica perturban localmente el campo magnético, imposibilitando así el uso de la brújula en las cercanías de los cuerpos intrusivos.

En general, se puede afirmar que las rocas intrusivas y plagiograníticas de los complejos básicos de la región antearco del Sur de América Central constituyen una fuente miscelánea, permanente, de sedimento desde hace por lo menos 75 millones de años.

\section{CONCLUSIONES}

1) Los fragmentos de roca de naturaleza intrusiva son componentes accesorios importantes, que se identifican por vez primera, en las areniscas cretácicas que sobreyacen al Complejo de Nicoya.

2) Las rocas-fuente de detrito plutónico se atribuyen a las intrusiones cretácicas de composición básica hasta intermedia de la secuencia ofiolítica.

3) En la fracción detrítica, se observa una relación relativamente proporcional entre el contenido de cristales de piroxeno detrítico, especialmente de piroxeno uralitizado, y el contenido de fragmentos líticos de origen plutónico. Esta relación sugiere que el piroxeno uralitizado es producto de la erosión de rocas intrusivas.

4) En particular, los fragmentos con intercrecimientos micrográficos de cuarzo y albita y el piroxeno uralitizado son considerados como productos específicos de la erosión de los plagiogranitos de composición intermedia del Complejo de Nicoya.

5) En este estudio se demuestra, que ambos componentes arriba mencionados pueden ser utilizados como parámetros cuantitativos de procedencia plutónica en el análisis modal de areniscas derivadas de complejos ofiolíticos.

6) La sedimentología de las areniscas evidencia que el detrito plutónico fue 
incorporado en la facies nerítica durante las transgresiones marinas sobre áreas expuestas, mientras que en el ambiente de talud submarino fue distribuido por corrientes de turbidez y flujos arenosos durante la caída del nivel del mar.

7) Las áreas de procedencia de detrito plutónico se localizan tanto en la Península de Nicoya como en la región del Cerro Barbudal, al norte del Golfo de Nicoya.

8) La edad de las areniscas, con base en las asociaciones de macroforaminíferos, permite datar como Campaniano la edad mínima de las intrusiones del Complejo de Nicoya.

9) La presencia de detrito plutónico en las areniscas cretácicas del noroeste de Costa Rica documenta una erosión que alcanzó los niveles inferiores de la secuencia ofiolítica en el Cretácico Tardío. Esto requirió, por consiguiente, largos períodos de exposición y denudación durante la formación del arco de islas de Costa Rica.

10) Los fragmentos de rocas intrusivas y los granos de pedernales radiolaríticos de las areniscas cretácicas pueden ser utilizados como indicadores paleotectónicos del levantamiento del orógeno de Costa Rica en el Campaniano Tardío. Este evento se correlaciona con el inicio de la Orogénesis Laramídica en Norteamérica.

11) Las rocas intrusivas del Complejo de Nicoya constituyen aún hoy día una fuente miscelánea de sedimento en el noroeste de Costa Rica.

\section{NOTA}

Partículas sedimentarias compuestas de hidróxidos de $\mathrm{Fe}$, producto de la meteorización en ambiente tropical (Johnsson, 1990).

\section{AGRADECIMIENTOS}

Expreso mi sincero agradecimiento a la colega Ángela Bolz (Stuttgart) por la revisión del manuscrito y las determinaciones de algunos de los macroforaminíferos. De igual forma agradez- co a Siegfried Kussmaul y a Teresita Aguilar (San José) por la ayuda prestada en la publicación de este trabajo.

\section{REFERENCIAS}

CALVO, C., 1987: Las calizas neríticas de la Vertiente Pacífica del norte de Costa Rica y sur de Nicaragua: Épocas y sistemas asociados con la apertura y evolución del margen convergente de la América Central meridional. - 165 págs. Escuela Centroamericana de Geología, Universidad de Costa Rica, San José (tésis inédita).

CALVO, C. \& BOLZ, A., 1994: Der älteste Inselbogen-Vulkanismus in Costa Rica. Marine Pyroklastika der Formation Loma Chumico (Alb bis Campan). - En:Seyfried, H. \& Hellmann, W. (eds.): Geology of an evolving island arc. Profil, 7: 235-264.

CALVO, C., 1996: Kretazische Subduktionsprozesse in Süd-Zentralamerika. - 216 págs.; Universidad de Stuttgart, Stuttgart (tesis $\mathrm{PhD}$ ).

DE JAMET, J., 1980: Mineralogía Óptica - Segunda parte: Descripción de los principales minerales de las rocas. - 105 págs.; Escuela Centroamer Geología, Universidad de Costa Rica, (folleto).

DICKINSON, W.R., 1985: Interpreting provenance relations from detrital modes of sandstones. - En: Zuffa, G.G. (ed.): Provenance of Arenites. NATO ASI Ser. C: Math. Phys. Sci. 148: 333-361.

DICKINSON, W.R. \& SUCZEK, C.A., 1979: Plate tectonics and sandstones composi- 
tions. - Bull. Am. Assoc. Petroleum Geol. 63: 2164-2182.

FISCHER, R. \& AGUILAR, T., 1994: Paleontology of an evolving island arc. - En Seyfried, H. \& Hellmann, W. (eds.): Geology of an evolving island arc. Profil, 7: 391-400.

FÜCHTBAUER, H., 1988: Sandsteine. - En Füchtbauer, H. (ed.): Sedimentpetrologie Teil II: Sedimente und Sedimentgesteine: 97-184; Schweizerbart, Stuttgart.

JOHNSSON, M.J., 1990: Overlooked sedimentary particules from tropical weathering environments. - Geology, 8: 107-110.

KUIJPERS, E.P., 1979: La Geología del Complejo Ofiolítico de Nicoya, Costa Rica. Inst. Geogr. Nacional Costa Rica, Inf. semestr. Julio-Diciembre 1979: 15-75.

KUSSMAUL, S., 1980: Petrografía de Rocas Igneas. - 122 págs. Escuela Centroamer. Geología, Universidad de Costa Rica, (folleto).

LUNDBERG, N., 1991: Detrital record of the early Central American magmatic arc: Petrography of intraoceanic forearc sandstones, Nicoya Península, Costa Rica. - Bull. geol. Soc. Am. 103: 905-915.

PETTIJOHN, F.J., 1949: Sedimentary rocks. 526 págs.; Harper \& Brothers, New York.
PROTTI, R., 1981: Geología de la planicie costera desde Jicaral, Puntarenas hasta Santa Rita, Nandayure, Península de Nicoya, Costa Rica. - 12 págs.; Inf. técn. Serv. Nac. Aguas Subterráneas (SENAS), San José.

SCHWEIKERT, U., 1997: Entstehung und Herkunft der „Ophiolithkomplexe“"Westpanamás. - 77 págs.; Universidad de Stuttgart, Stuttgart (tésis inédita).

TRÖGER, W.E., 1967: Optische Bestimmung der gesteinsbildenden Minerale. Teil 2: Textband. - 822 págs.; Schweizerbart, Stuttgart.

WILDBERG, H.G.H., 1984: Der Nicoya-Komplex, Costa Rica, Zentralamerika: Magmatismus und Genese eines polygenetischen Ophiolith-Komplexes. - Münster Forsch. Geol. Paläont. 62: 1-123.

WILDBERG, H.G.H., 1987: High level and low level plagiogranites from the Nicoya ophiolite complex, Costa Rica, Central America. - Geol. Rundsch. 76: 285-301.

WOZASEK, S., 1997: Provenanzanalyse mit Schwermineralen: Untersuchungen tertiärer Sandsteine des Forearc-Bereiches (Halbinsel Azuero) und des Backarcs-Bereiches (Río Changuinola) im westpanamaischen Inselbogensystem. - 78 págs.; Universidad de Stuttgart, Stuttgart (tésis inédita). 